\title{
AS AVALIAÇÕES EM LARGA ESCALA E SUA REPERCUSSÃO NO CHÃO DA ESCOLA
}

\author{
Iara Holanda Machado ${ }^{1}$ \\ Marcel Pereira Pordeus ${ }^{2}$
}

RESUMO: O tema Avaliação é um dos mais discutidos entre os pesquisadores e os profissionais da educação. Por muito tempo discutia-se, apenas, sobre as avaliações realizadas na escola, isso é, a avaliação da aprendizagem. Esse cenário foi modificado a partir da década de 1990, quando as discussões sobre avaliação externa ganharam centralidade nas agendas governamentais, tornando-se, também, foco de muitos estudos acadêmicos. Nesse estudo, buscou-se refletir sobre o papel que as avaliações têm assumido no contexto escolar brasileiro, destacando possíveis avanços, limites e os efeitos práticos na escola. Trata-se de uma pesquisa qualitativa, de caráter bibliográfico e documental, baseada, fundamentalmente, em estudos que tratam dessa temática, a exemplo de Frigotto, Fonseca, Cassasus, dentre outros e de dados do Instituto Nacional de Estudos e Pesquisas Educacionais Anísio Teixeira (INEP). Os resultados da pesquisa apontaram para a seguinte compreensão: visto que o sistema cobra resultados, é necessária uma mudança na forma de planejar e executar o trabalho docente na escola. O planejamento deve incorporar as matrizes de referência exigidas nas avaliações externas, possibilitando aos educandos o desenvolvimento das habilidades necessárias e, assim, alcançar melhores resultados.

Palavras-chave: Políticas Públicas. Avaliação Externa. Repercussão na Escola.

\section{INTRODUÇÃO}

No Brasil, a prática de Avaliação em larga escala, embora seja amplamente divulgada e percebida, é recente e surgiu impulsionada por um contexto social econômico que teve início com a abertura política em 1985. Após a promulgação da nova Constituição Federal em 1988, começou a estruturar-se um grande projeto mundial por meio de organismos internacionais, a saber: a Conferência Mundial sobre Educação para Todos em Jomtien (1990), na Tailândia, quando a Comissão Internacional sobre a Educação para o Século XXI e o Banco Mundial (BM), elaboraram documentos que influenciariam a

\footnotetext{
I Possui graduação em Pedagogia pela Universidade Estadual do Ceará (1988). Tem experiência na área de matemática, com ênfase em álgebra. E-mail: ihmac@yahoo.com.br.

2 Possui graduação em Letras pela Universidade Federal do Ceará. Mestre em Planejamento e Políticas Públicas pela Universidade Estadual do Ceará.E-mail: marcel.pordeus@aluno.uece.br.
} 
elaboração da nova Lei de Diretrizes e Bases da Educação Nacional (BRASIL, 1996). A partir desses eventos, a Educação passou a ocupar lugar de destaque na agenda das políticas públicas e o Ministério da Educação, MEC, assumindo o papel de monitoramento das políticas nacionais da educação básica. A partir do Plano de Reforma do Estado, a gestão por resultados educacionais ganhou ênfase e foi incorporada à educação.

Essa política de avaliação se materializa no termo 'eficácia', cujo sentido marca a linguagem dos documentos oficiais do Ministério de Educação e Cultura (MEC), e as prerrogativas das diversas políticas educacionais. As escolas brasileiras têm sido alvo, nas últimas décadas, de diversas avaliações externas implementadas pelo governo federal, por governos estaduais, e, mais recentemente, por governos municipais. No cenário contemporâneo, a Avaliação assume posição de centralidade, tornando-se uma atividade cada vez mais complexa, evoluindo do estágio das micro avaliações para o das macro avaliações.

Percebe-se uma evolução no foco da avaliação, inicialmente voltada para a aprendizagem, restrita ao universo da sala de aula, para uma dimensão mais ampla, envolvendo os sistemas e as instituições educacionais. Levados por essa onda, os vários Sistemas Educacionais de diferentes países, principalmente daqueles em desenvolvimento, a exemplo dos países da América Latina, como é o caso do Brasil, passaram a desenvolver, por iniciativa própria, indução e/ou até imposição das agências internacionais, em especial as instituições de financiamento, mecanismos ou políticas de Avaliação Educacional dos seus sistemas de ensino.

Tais sistemas de avaliação focalizavam, prioritariamente, a mensuração do rendimento escolar dos alunos, com o objetivo de diagnosticar o desempenho dos sistemas em função dos investimentos decorrentes dos empréstimos contraídos. Com objetivos que se modificaram ao longo dos anos, paulatinamente, essas avaliações tendem a ser absorvidas pela dinâmica da escola, passando a compor a rotina de sua organização e a integrar o calendário escolar.

Avaliações externas são aquelas elaboradas, organizadas e efetuadas por atores externos às escolas, geralmente órgãos superiores ou intermediários da estrutura educacional, tais como diretorias de ensino, secretarias de educação municipais ou 
estaduais e o próprio Ministério da Educação, que podem fazê-las diretamente, ou por meio da contratação de empresas especializadas em Avaliação Educacional.

Motivos diversos impulsionaram esse movimento, entre os quais estão as iniciativas do governo federal de criação do Sistema de Avaliação da Educação Básica (SAEB), em 1990, do Exame Nacional de Cursos (ENC), em 1995 e do Exame Nacional do Ensino Médio (ENEM), em 1998, que tiveram, sem dúvida, um papel preponderante. Seguindo o governo federal alguns governos estaduais intensificaram esse movimento com a criação de seus próprios sistemas de avaliação do Ensino Fundamental, sendo os pioneiros os Estados do Ceará (1992), Minas Gerais (1992) e São Paulo (1996). Dessa feita, o Estado do Ceará iniciou, em 1992, suas primeiras experiências de avaliação do seu sistema, como política pública para o setor.

Neste Estado, a Avaliação Educacional ganhou forma com a institucionalização do seu Sistema Permanente de Avaliação da Educação Básica do Ceará (SPAECE), que vem evoluindo de forma sistemática a cada ciclo de aplicação, incorporando novas metodologias de pesquisa e inovações tecnológicas. Admite-se que a análise teórica realizada sobre essa temática, entendida como condição para a propalada 'qualidade da educação', assunto abordado nesta pesquisa apenas como pano de fundo, não representa, em si, nenhuma novidade, uma vez que já existe uma vasta literatura que discute essa questão sob perspectivas igualmente variadas; ainda assim, advoga-se a necessidade de retomar e ressignificar essa discussão, justamente pelo fato de que ela continua sendo uma das principais preocupações das atuais políticas educacionais no Brasil e, portanto, os maiores desafios para aqueles que estão à frente dessas instituições.

Com a ideia de fornecer informações sobre o desempenho e resultados dos sistemas educativos, escolas, famílias e sociedade aparecem, dentre outros, como principal justificativa nos documentos oficiais de criação das avaliações externas (BRASIL, 1994), ressalta-se a importância do levantamento e coleta de dados para subsidiar as ações nos âmbitos da gestão da política educacional. De modo geral, tais avaliações concentraram-se em torno da aplicação de testes para a aferição de competências e habilidades em Língua Portuguesa e Matemática para obtenção de seus resultados.

É relevante para os processos educacionais, sistematizar informações sobre os sistemas educativos, porém não é suficiente para a constituição de uma avaliação, seja 
externa ou interna, quando o objetivo é a obtenção de dados para elaborar propostas de investimentos e ações para a melhoria da qualidade da educação. Avaliar é um processo que pode ter como parte integrante o levantamento sistemático de informações dos alunos em testes padronizados, mas não se esgota nele. A análise dos dados obtidos, a produção de juízos de valor sobre eles e a utilização dos resultados alcançados para direcionar de ações são etapas indissociáveis do ato de avaliar.

No caso das redes públicas de ensino, os resultados das avaliações externas têm sido utilizados com o propósito de melhorar os índices de aprendizagem de cada Unidade de Ensino. Para isso, é necessário um grande empenho de professores e equipes gestoras dessas Unidades Educacionais, para alcançar as metas definidas. A valorização da etapa inicial da avaliação, o levantamento, coleta e sistematização de informações, não podem superar o estímulo para a apropriação das etapas seguintes do processo avaliativo.

Nele são abordados e problematizados usos dos resultados de avaliações externas por equipes de gestão escolar de escolas de ensino básico, na perspectiva de sua utilização no trabalho pedagógico, visando à melhoria da qualidade do ensino. Existe uma relação intrínseca entre avaliações externas e gestão escolar para resultados. A rigor, a elevação do rendimento da aprendizagem na rede escolar pública, se tornou um dos objetivos principais perseguidos pelas políticas de educação em vários países do mundo.

Estimulados pela apresentação de padrões, projetos e resultados divulgados por organismos multilaterais como a Organização das Nações Unidas (ONU), Organização das Nações Unidas (UNESCO), Fundo das Nações Unidas para a Infância (UNICEF) e Organização para a Cooperação e Desenvolvimento Econômico (OCDE), dentre outros, ao lado da exposição modelar de alguns países cujas experiências são tomadas como referenciais, programas e projetos têm sido elaborados visando à elevação de resultados de aprendizagem mensurados através de instrumentos quantitativos cada vez mais universalmente acatados.

A pesquisa qualitativa foi usada neste estudo, pois, conforme Minayo (2006), não objetiva o alcance de uma verdade absoluta conceitual e plenamente aceita, haja vista que seu conteúdo não determina se existe certo ou errado, mas sim, discute a possibilidade de uma compreensão lógica e sistêmica que cerceia a prática envolvida na realidade avaliada. Assim, o pesquisador está mais interessado em analisar significados, motivos, 
valores e atitudes, possibilitando uma avaliação mais profunda das relações e seus processos.

Para tanto, os critérios utilizados neste tipo de estudo foram a coerência e a lógica, a consistência de seus conteúdos e materiais selecionados, a intersubjetividade, a objetivação e a originalidade (GIL, 200I). O desejo de aprofundar a problemática em pauta emerge de inquietações e reflexões realizadas ao longo da trajetória dessa pesquisadora, sobretudo, enquanto professora da rede básica de educação do Estado do Ceará. A escolha desse objeto particular de investigação, entretanto, decorre de sua atuação por 20 anos em uma das escolas cearenses.

A presente pesquisa procurou respostas para a questão norteadora, a saber: Que mudanças as avaliações externas têm provocado na educação pública cearense? Dessa questão, surgiram outros questionamentos igualmente importantes para a construção dessa pesquisa: $O$ que é avaliar? Como tem sido usadas essas avaliações na escola? Para que servem realmente, as avaliações externas? A quais interesses elas atendem?

O interesse por esse tema surgiu da vivência da pesquisadora, como professora e gestora de escola pública estadual cearense. Avaliação externa ainda é um tema muito polêmico e gerador de muitas discussões, principalmente no âmbito escolar onde alguns concordam outros discordam; alguns acreditam na sua eficácia, outros condenam veementemente. Para compreender melhor essa temática, a pesquisadora resolveu estudar alguns autores buscando respostas para as seguintes indagações: Como surgiram? Em que contexto? Para que servem? E acompanhar o desenvolvimento desse processo na escola em que trabalha durante o ano de 2017 para melhor entender a importância dessas avaliações.

\section{POLÍTICAS PÚBLICAS EDUCACIONAIS NO CONTEXTO DA REFORMA DO ESTADO BRASILEIRO}

O mundo contemporâneo passa por profundas mudanças na política, na cultura, na economia e em outras áreas do saber. A educação não fica à margem desse fenômeno, sobretudo nos países em desenvolvimento, a exemplo do Brasil. Parte-se da premissa de que o estudo em questão está intimamente ligado ao movimento do grande capital que vem impondo ao mundo capitalista e, sobretudo, aos países da periferia do sistema, profundas mudanças que afetam diretamente seus sistemas de ensino, a exemplo 
do que ocorreu no Brasil, com a contrarreforma realizada na educação brasileira a partir da década de 1990.

Desde aquele período, as políticas educacionais brasileiras tendem a colocar em prática os 'aconselhamentos' dos documentos produzidos pelas as Agências de Financiamento, como o Banco Mundial e o Fundo Monetário Internacional (FMI), que passaram a dizer o que era melhor para a nossa educação, em vista dos interesses do capital em pleno processo de expansão, contrariando as mobilizações sociais que reivindicavam uma sociedade mais justa e igualitária para todos e uma educação em que as pessoas fossem críticas, criativas, autônomas, solidárias, participativas e conscientes de seus direitos.

Com a crise estrutural do sistema capitalista deflagrada nos anos de 1970 (MÈZSÀROS, 2002), os países periféricos são atingidos fortemente pela nova ofensiva capitalista e passam a orientar suas políticas com base nos 'aconselhamentos' dos documentos produzidos e impostos pelos Organismos Internacionais, notadamente o Banco Mundial (BM) e do Fundo Monetário Internacional (FMI).

Como consequência, a escola passa a orientar seus currículos pelo viés mercadológico, tornando-se lócus privilegiado para formar trabalhadores do novo tipo, flexíveis, bem ao gosto dos mercados em tempos de globalização. É fato que a educação brasileira vem passando por mudanças significativas, ora no sentido de melhoria da sua estrutura física, mas se apresenta, ainda, com muitos problemas, desde as condições de trabalho dos docentes, a frágil formação para o exercício em sala de aula e a inegável desvalorização desse profissional, o que é visualizado pelos baixos salários da categoria.

As políticas neoliberais para a educação têm como escopo adaptar as escolas às exigências do mundo globalizado e das novas tecnologias como condição para dialogar com os tempos atuais. Torna-se campo de disputa para o empresariado nacional que exige dessa, compromisso com a formação da classe trabalhadora, sobretudo, para os serviços elementares da cadeia produtiva. Desde então, a escola alinha seu discurso sob a ótica da visão empreendedora dos jovens, resgatando, fortemente, o discurso do protagonismo e do empreendedorismo juvenil.

A década de 1990, no Brasil, destaca-se como o período em que o país ensaiava seus primeiros passos na conformação da doutrina neoliberal, consubstanciada numa ampla reforma do Estado e do seu aparato estatal, com rebatimentos diretos nas políticas 
sociais. Nesse contexto, modifica-se profundamente a atuação do Estado que passa a ser regido pela lógica do ajuste fiscal e da racionalidade financeira do Estado mínimo.

$\mathrm{Na}$ perspectiva de Peroni (2003, p. 50), o Estado mínimo limita-se a gerir compensações, evidenciando-se, claramente, que “[...] não se trata de Estado mínimo genericamente. É o Estado de classe, hegemonizado pelas elites do setor financeiro, neste período particular do capitalismo, e que se torna mínimo apenas para as políticas sociais." Sob tal perspectiva, “[...] o Estado reduz seu papel de executor ou prestador direto de serviços, mantendo-se, entretanto, no papel de regulador e provedor ou promotor destes, principalmente dos serviços sociais como educação e saúde” (BRASIL, 1995, p.13).

O novo papel do Estado, no que tange à oferta das políticas sociais (direitos sociais inscritos na Constituição), passou por uma crescente desconstitucionalização, no sentido da redução do 'Custo Brasil', que supostamente encarecia os produtos brasileiros, impedindo-os de obter competitividade no mercado internacional. Para as classes dominantes (hegemônicas), a diminuição de tal custo exigia a flexibilização das leis trabalhistas, somadas à desregulamentação do mercado de trabalho.

Acreditava-se que, por meio dessas medidas, o País criaria maior número de empregos, aumentando a competitividade dos empresários brasileiros no contexto dos mercados mundializados; mas isso não ocorreu. O modelo de reforma aplicado ao Estado brasileiro cumpre destacar, baseia-se, fundamentalmente, nos 'aconselhamentos' dos organismos financeiros internacionais, notadamente o Banco Mundial e o Fundo Monetário Internacional (FMI), representantes do grande capital financeiro, que sugeria que a reforma deveria interditar direitos sociais conquistados na Constituição de 1988, retirando do Estado as suas funções democráticas, destituindo, assim, seu caráter público, passando a ser conduzido por meio de estratégias gerenciais e sustentado na lógica instrumental e privatista do mercado.

É inegável a pronta disposição do governo FHC em atender aos reclames dessas agências e das elites econômicas e políticas nacionais, o que ficou comprovado no processo de desmantelamento do Estado e seus mecanismos de atenção no campo social e na aplicação de políticas regulatórias em áreas consideradas estratégicas para o povo brasileiro (saúde, educação, segurança e outras), sempre no sentido de favorecer aos grandes grupos econômicos nacionais e as empresas transnacionais. 
Como indicam Frigotto e Ciavatta (2003, p. 103): “[...] se trata de um governo que conduziu as diferentes políticas de forma associada e subordinada aos organismos internacionais, gestores da mundialização do capital e dentro da ortodoxia da cartilha do credo neoliberal”, cujo núcleo central é a ideia do livre mercado e da irreversibilidade de suas leis.

O novo papel do Estado, no que tange à oferta das políticas sociais (direitos sociais inscritos na Constituição), passou por uma crescente desconstitucionalização, na direção da redução do Custo Brasil que, supostamente, encarecia os produtos brasileiros, impedindo-os de obter competitividade no mercado internacional. Para as classes dominantes, a diminuição de tal custo exigia a flexibilização das leis trabalhistas, somadas à desregulamentação do mercado de trabalho.

Afirma-se que, dessa maneira, o País iria gerar muitos empregos formais, pois estaria assegurado ao empresariado, o aumentando a competitividade, fatores de sucesso no contexto dos mercados mundializados. Ao contrário do discurso hegemônico, a reforma materializou-se por meio de expressivos cortes nos gastos sociais, favoreceram apenas as frações de classe detentoras do grande capital (nacional e internacional), na medida em que conseguiram desarticular as redes de proteção social, além de impor profundas mudanças na organização do mundo do trabalho, elementos que foram utilizados como mecanismos de destruição organizacional da classe trabalhadora.

Longe de representar avanços no campo dos direitos sociais, significou, ao contrário, retrocessos de todo tipo, evidenciados pela retirada de direitos sociais, direitos, esses, conquistados a duras penas como fruto das lutas históricas dos trabalhadores. Evidentemente, a referida reforma não teria dado certo se não tivesse sido acompanhado também de amplas mudanças na estrutura da legislação brasileira, sobretudo com uma revisão da Constituição Federal (BRASIL, 1988) e, no caso da Educação, a lei de Diretrizes Nacionais da Educação Básica, lei no. 9.394/96 (BRASIL, 1996) e um conjunto de Leis e Decretos subsequentes a ela correlatos, que serviram de apoio para a implementação de cada medida impetrada no campo da educação sob o manto do neoliberalismo.

É nesse contexto de forte presença dos organismos internacionais na formulação e execução, através de seus funcionários e consultores das políticas educacionais, que se articulam e se desenvolvem as reformas educativas, assunto que será 
tratado na próxima sessão. No contexto neoliberal, a educação é concebida como mercadoria e que, para ter acesso a ela, é preciso pagar. Para aqueles que não podem comprá-la, o Governo oferece paliativos que, em vez de contribuir para a emancipação dos sujeitos, servem para produzir mão de obra barata, utilizada como massa de manobra que abastece uma rede de interesses particulares, ao mesmo tempo em que direciona e fortalece cada vez mais o poder nas mãos de poucos em detrimento da escassez de muitos. Convém ressaltar, oportunamente, que tal estratégia se alinha aos 'aconselhamentos' advindos das agências internacionais de financiamento para projetos educacionais de jovens, moradores da periferia do capitalismo.

\section{CONCLUSÃO}

Neste estudo, cujos objetivos ressaltaram uma análise das avaliações externas, tema em destaque nas duas últimas décadas no cenário da educação brasileira, após análise da leitura de vários autores e de alguns pontos da legislação educacional, verificou-se que elas constituem um importante instrumento para a melhoria da qualidade da educação.

Foi apresentado o contexto social e político em que as mesmas surgiram e como foram ganhando destaque e se tornando cada vez mais essenciais. Neste trabalho ficou visível a grande preocupação das escolas públicas com os resultados das avaliações externas e como elas vêm se adequando e preparando os alunos para os testes. Foi visto, também, como o Governo Federal tem destinado mais recursos para as Secretarias de Educação, tentando aproximar, o máximo possível, os resultados do IDEB em relação à média mundial e, assim, atender aos acordos internacionais.

Ficou claro que quando a Avaliação se torna padronizada nacionalmente e com caráter controlador, as especificidades são desconsideradas como aspectos: geográficos, sociais, econômicos estruturais e de formação dos profissionais da educação, fatores que interferem no processo pedagógico e necessitam ser analisados e considerados no processo de avaliação das escolas de educação básica.

Esses diversos fatores afetam diretamente o rendimento escolar gerando dificuldades no processo de ensino-aprendizagem por parte dos alunos e consequentemente influenciando índices das provas externas aplicadas pelas secretarias de educação e pelo MEC. Na visão dos alunos, as avaliações externas, como a Prova Brasil e outras, têm 
contribuído para a melhoria do seu aprendizado, porém, encontraram dificuldades na realização das mesmas devido às provas serem muito extensas (os mesmos não têm paciência pra ler), e com alguns conteúdos os quais eles ainda não tinham o domínio necessário para a realização da mesma.

As escolas passaram a desenvolver o seu trabalho de forma que pudesse estimular o aluno a aprender com projetos de leitura, trabalhando também a elevação da autoestima dos alunos individualmente, e em grupo para que houvesse motivação para a aprendizagem. Fez-se necessária uma reflexão constante junto ao conjunto de educadores questões fundamentais como: o que os alunos aprenderam e o que ainda não foi apropriado? Por que os alunos não aprenderam? Onde está o problema? Nos alunos, na escola, nas metodologias de aprendizagem? Que ações precisam ser empreendidas pela gestão escolar e pelos professores de cada turma? O que está dando certo e o que deve ser mudado?

Correções de rotas foram necessárias e novas metodologias implementadas. Com os professores foram feitos diversos estudos sobre a "Avaliação no processo de ensino e aprendizagem", o que facilitou a utilização dos instrumentos de avaliação adequados para cada situação de aprendizagem, a compreensão da sua finalidade e objetivo, e o que se deseja alcançar por meio dele. Constatou-se que a função da avaliação é oferecer suporte para a tomada de decisão, visando à melhoria da qualidade do ensino e aprendizagem, por meio da análise das ações em desenvolvimento no âmbito escolar.

Essa ação foi importantíssima e contribuiu muito para melhoria do trabalho dos professores em sala de aula, e para melhorar os resultados nas avaliações externas. Foi visto que as práticas desenvolvidas e o acompanhamento sistemático, que vêm acontecendo nas escolas cearenses, após estudos dos resultados das avaliações externas, foram de grande eficácia e mostraram resultados surpreendentes.

Pode-se, então, concluir que as Avaliações Externas fornecem dados que mostram onde estão as principais dificuldades de aprendizagem encontradas na escola pública, dando o direcionamento para um planejamento mais eficaz, e contribuindo para o cumprimento da função social da escola na sociedade democrática, que é a garantia de ensino e de aprendizagem de qualidade para todos os alunos, além de efetivamente prestar 
contas à sociedade das ações realizadas no que diz respeito à construção de um projeto educativo de eficácia social e subsidiar as políticas públicas.

\section{REFERÊNCIAS}

BANCO MUNDIAL, 1995. Relatório sobre o Desenvolvimento Mundial: O Trabalhador e o Processo de Integração Mundial. In: Washington, D.C. BEISIEGEL, Celso Rui. A qualidade do ensino na escola pública. Brasília: Líber Livro, 2006.

BRASIL. Ministério da Administração Federal e da Reforma do Estado. Plano diretor da reforma do aparelho do Estado. Brasília, DF, 1995. BRASIL. Lei de Diretrizes e Bases da Educação Nacional. Lei número 9.394, 20 de dezembro de 1996.

CEARÁ. Secretaria de Educação Básica. Coordenadoria de Avaliação e Acompanhamento da Educação. Sistema Permanente de Avaliação da Educação Básica do Ceará: SPAECE 2006: Relatório Geral. Fortaleza: SEDUC; Rio de Janeiro: Fundação CESGRANRIO, 2007.

CEARÁ. Secretaria de Educação Básica. Coordenadoria de Desenvolvimento Técnico Pedagógico. Núcleo de Pesquisa e Avaliação Institucional. Sistema Permanente de Avaliação do Ensino do Ceará- SPAECE/98- Documento Síntese. Fortaleza, 1999.

CEARÁ. Secretaria da Educação Básica. Coordenadoria de Planejamento e Política Educacional. Núcleo de Pesquisa e Avaliação Educacional. SPAECE-NET: os novos caminhos da avaliação educacional - Relatório Geral - 200I. Fortaleza: SEDUC / LEME Laboratório de Estatísticas e Medidas Educacionais. (mimeo).

CEARÁ. Secretaria da Educação Básica. Coordenadoria de Planejamento e Políticas Educacionais. Célula de Pesquisa e Avaliação Educacional. Sistema Permanente de Avaliação da Educação Básica do Ceará - SPAECE 2004 - Relatório Regional. Crede 15 Tauá. Fortaleza: SEDUC/CESGRANRIO, 2005.

FREIRE, Paulo. Pedagogia da autonomia. 9. ed., Rio de Janeiro: Paz e Terra, 1998.

FRIGOTTO, G. Educação, crise do trabalho assalariado e do desenvolvimento: Teorias em conflito. In: FRIGOTTO, G. (Org.). Educação e crise do trabalho: perspectiva de final de século. Petrópolis: Vozes, 1998. (Coleção Estudos culturais em educação).

FRIGOTTO, G.; CIAVATTA, Maria. Educar o trabalhador cidadão produtivo ou o ser humano emancipado?. Trab. educ. saúde [online]. 2003,

GIL, Antônio Carlos. Gestão de pessoas: enfoque nos papeis Profissionais. São Paulo: Atlas. 200I.

MINAYO, Maria Cecília de Souza (org.). Pesquisa social: teoria, método e criatividade. Petrópolis, RJ: Vozes, 2010.

OLIVEIRA, A. P. de M.A. Prova Brasil como política de regulação da rede pública do Distrito Federal. [Dissertação de Mestrado] 276 f. - Programa de Pós-Graduação em Educação. Brasília: Universidade de Brasília, 2oıI. 